\title{
Analysis of Drainage Rate Variation of Molten Iron and Slag from Blast Furnace during Tapping
}

\author{
Masakazu IIDA, Kazuhiro OGURA and Tetsui HAKONE \\ Materials Development Dept., JEF Refractories Corporation, 1576-2 Higashioki, Nakahiro, Ako, Hyogo 678-0232 Japan.
}

(Received on November 2, 2007; accepted on January 22, 2008)

\begin{abstract}
Despite its importance in practical blast furnace $(B F)$ operation, the dominant factors to control drainage rate or tapping time have not been well studied. In most cases, short tapping time has been attributed to rapid tap hole diameter enlargement. On the other hand, the experiential tendency about positive correlation between furnace hearth bottom temperature and drainage rate has been widely recognized.

In order to examine the dominant factors to control the liquid drainage rate or tapping time at BF, a simulative calculation model is introduced, where the liquid drainage path consists of coke particles packed layer (coke filter) and tapping hole and the overall drainage rate is determined as one of smaller fluid rate in coke filter or tapping hole. For calculating the fluid rate in coke filter, a hypothesis that liquid iron and slag in coke filter is driven toward the tap hole entry point consuming the coke particles, whose extent depends on molten iron $\mathrm{C}$ saturation degree and $\mathrm{FeO}$ fraction in molten slag, was introduced.

The calculation results present good matches with the observed tapping operation. This result can be explained by the two influences of low permeability zone formation or elimination at furnace hearth. Considering the two influences of low permeability zone formation, (1) to lower hearth bottom temperature and (2) to induce low $\mathrm{C}$ saturation of pig iron due to short traveling time in liquid pool to tap hole entry point, the simulation result conforms to the above mentioned experiential tendency.
\end{abstract}

KEY WORDS: iron making; blast furnace; tapping time; drainage rate; mathematical model; hearth bottom temperature; tap hole mix; low permeability zone.

\section{Introduction}

The drainage of molten iron and slag out of blast furnace (hereinafter referred to as BF), "tapping" in the operation field term, is carried out usually from two tap holes alternately. Tapping starts by opening the tap hole which has been plugged with tap hole mix in the previous operation. The drainage or tapping rate, whose initial value is smaller than iron and slag production rate in BF, increases in accordance with the progress of tapping. Once the tapping rate exceeds iron and slag production rate, the slag level in BF is gradually lowered. When the slag level in the furnace reaches close to tap hole entry position, the tapping is ended with tap hole mix plugging, followed by the tapping start at the other tap hole. The time duration is called as tapping time.

Lengthy tapping time is appreciated for heavy duty alleviation in tapping operation as well as reduction in tap hole mix consumption. From this standpoint, highly durable tap hole mix with smaller erosion speed is required. Even using a certain tap hole mix with constant refractories compositions and the similar erosion properties, the tapping time broadly varies occasionally in the practical operation, for example, from 120 to $240 \mathrm{~min}$. Such a large fluctuation in tapping time is unexplainable only with the refractory wear rate of tap hole mix, because the refractory properties influencing on its wear rate, such as chemical erosion, mechani- cal abrasion, thermal shock peeling, have been improved so as to establish constant and stable performance, and the variations in operational factors influencing on refractory wear rate, such as hot metal temperature, slag ratio, metal and/or slag compositions, are not large enough to give irrelevant impacts on tap hole mix wear.

This outlook is authentically supported by the investigation of Nishioka et $a l .{ }^{1)}$ They calculated the drainage rate variation during tapping taking account of the pressure drop of fluids through a constant length tap hole with actually measured tap hole diameter change and compared to the observed one, and concluded that it was not possible to describe the drainage rate variation only by tap hole diameter enlargement. They also suggested that a conformity between observed and calculate drainage rate variation could be achieved only when assuming that tap hole length is shortened from $4 \mathrm{~m}$ to $1 \mathrm{~m}$, which is apparently unrealistic and denied by the reports of Yamanaka et al. ${ }^{2)}$ and Ando et $a l^{3)}$ on the BF tap hole boring studies.

Whilst, an apparent relation between BF hearth bottom temperature and tapping time is widely recognized, that is, the lower hearth bottom temperature, the shorter tapping time. The change in hearth bottom temperature is explained with formation and disappearance of low permeability zone in the hearth, ${ }^{4-7)}$ whose influences on tap hole refractory wear is thought to be quite small or null.

In this report, introducing a model in which the drainage 

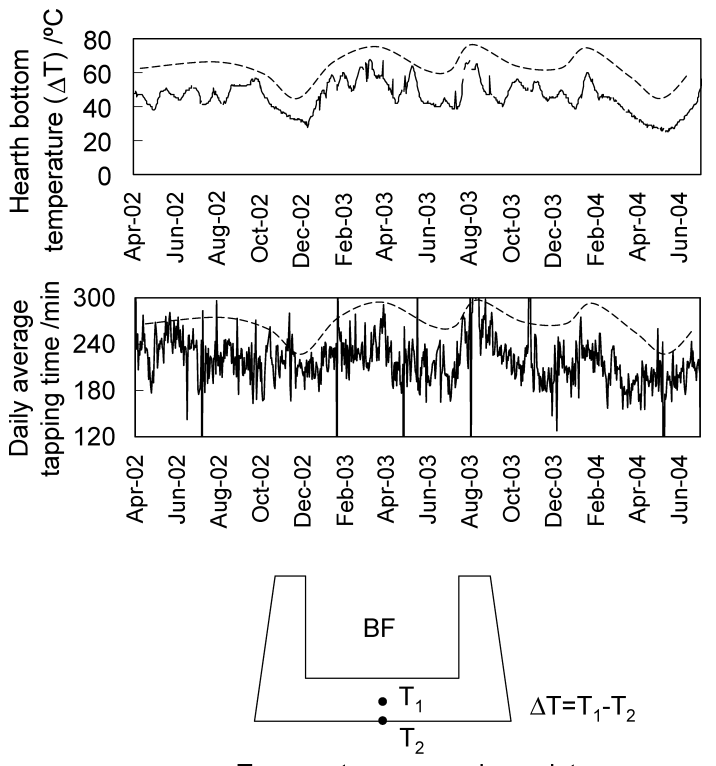

Temperature measuring point

Fig. 1. Trend of hearth bottom temperature $(\Delta \mathrm{T})$ and tapping time at BF "A".

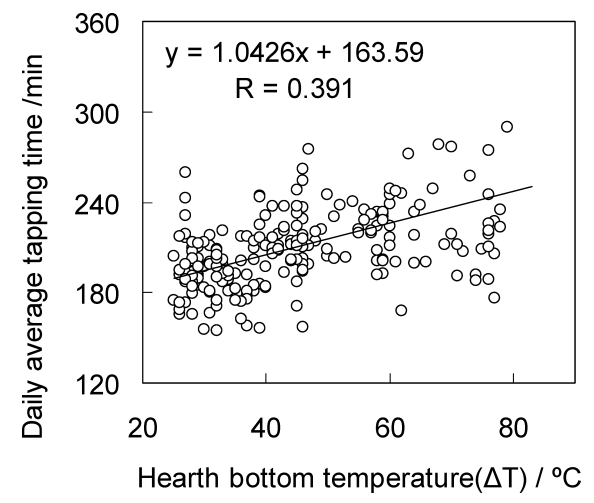

Fig. 2. Tapping time dependency on hearth bottom temperature $(\Delta \mathrm{T})$ at $\mathrm{BF}$ " $\mathrm{A}$ ".

path of fluid out of BF consists of coke filter layer and tap hole tube, the authors discuss the extents of influences of refractory and operation factors on tapping time variation.

\section{Tapping Data in Commercial BF Operation}

Figure 1 shows long term chronological trends of hearth bottom temperature $(\Delta \mathrm{T})$ and daily basis average tapping time at BF "A" (over $4500 \mathrm{~m}^{3}$ in Japan, alternating consecutive tapping). Two trends indicate the relationship that the tapping time was relatively longer at the time period of high hearth bottom temperature. These data are summarized into Fig. 2. The similar tendency has been recognized at some other BFs. Figure 3 shows the taping time dependencies on hearth bottom temperature in case of BF "B" (over $4500 \mathrm{~m}^{3}$ in Japan, alternating consecutive tapping). Positive correlation is also recognized. At BF " $\mathrm{B}$ ", contributions of chemical compositions of iron and slag to tapping time are recognized as shown in Figs. 4 and 5. Larger tapping time is achieved when carbon content in molten iron increased or $\mathrm{FeO}$ in molten slag decreased. Carbon content in molten iron increases as hearth bottom temperature rises as shown in Fig. 6. On the other hand, no clear correlation between

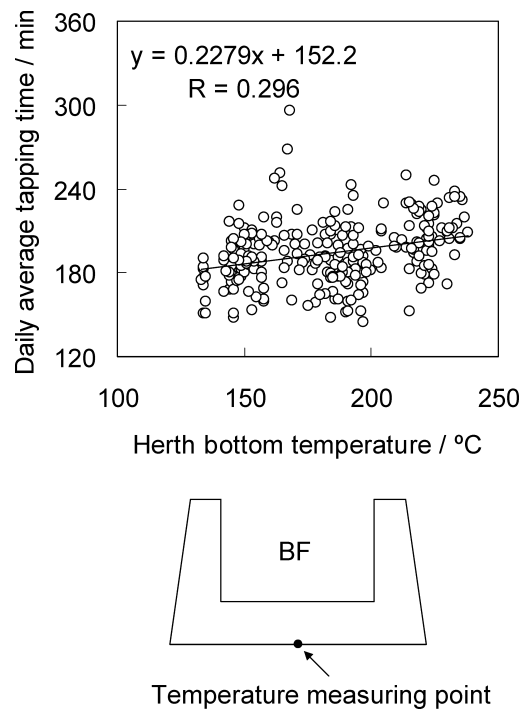

Fig. 3. Tapping time dependency on hearth bottom temperature at $\mathrm{BF}$ "B".

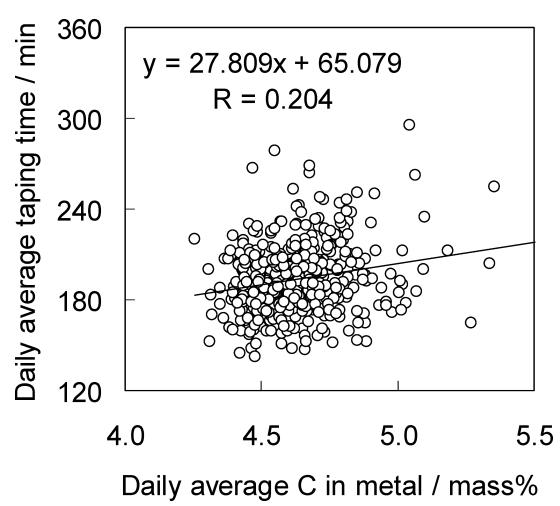

Fig. 4. Tapping time dependencies on carbon content in metal at $\mathrm{BF}$ “B”.

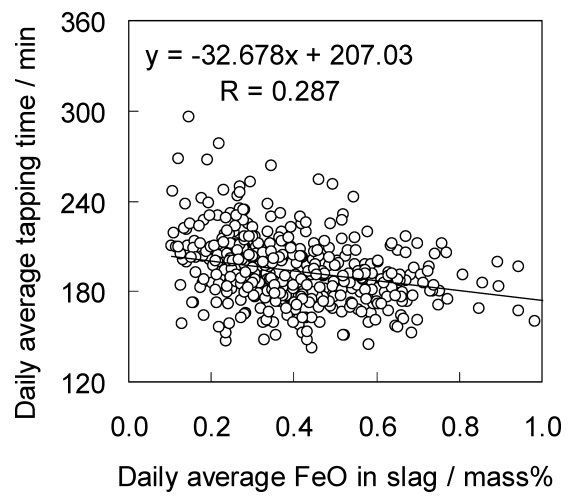

Fig. 5. Tapping time dependencies on $\mathrm{FeO}$ fraction in slag at BF "B".

$\mathrm{FeO}$ fraction in molten slag and hearth bottom temperature was recognized as shown in Fig. 7.

Figure 8 shows the changes of the drainage rate at certain tapping operations at BF "A". (A) and (B) in Fig. 8 are the typical data representing high and low hearth bottom temperature, respectively, with almost similar refractory specifications of tap hole mix. Figure 8 indicates that the longer tapping time at higher hearth bottom temperature period is the result of smaller drainage rate acceleration. Theoretically, tap hole diameter enlargement rate influences 


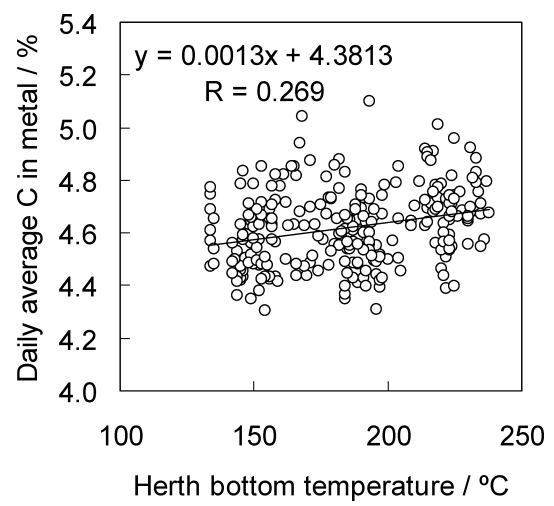

Fig. 6. Carbon content in metal as a function of hearth bottom temperature at $\mathrm{BF}$ " $\mathrm{B}$ ".

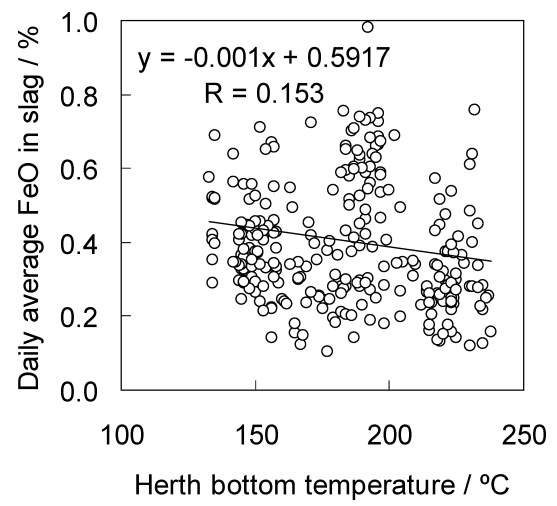

Fig. 7. FeO content in slag as a function of hearth bottom temperature at $\mathrm{BF}$ " $\mathrm{B}$ ".

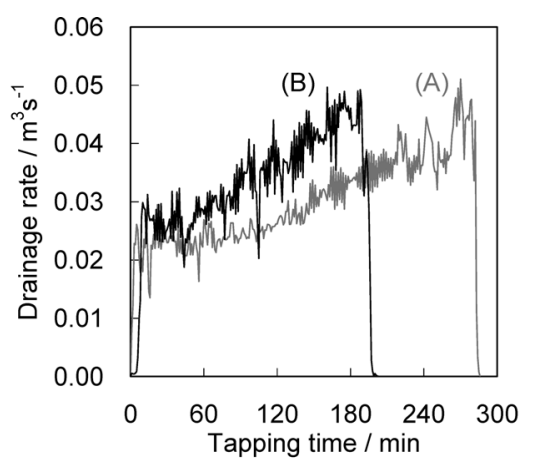

\begin{tabular}{|l|c|c|}
\hline Period & $(\mathrm{A})$ & $(\mathrm{B})$ \\
\hline $\begin{array}{l}\text { Hearth bottom temperature } \\
(\Delta \mathrm{T}) /{ }^{\circ} \mathrm{C}\end{array}$ & 61 & 32 \\
\hline Hot metal temperature $/{ }^{\circ} \mathrm{C}$ & 1516 & 1496 \\
\hline $\mathrm{C}$ in metal $/$ mass $\%$ & 4.51 & 4.27 \\
\hline $\mathrm{FeO}$ in slag $/$ mass $\%$ & 0.28 & 0.32 \\
\hline
\end{tabular}

Fig. 8. Changes of the drainage rate at certain tapping operations at BF "A".

on the drainage rate acceleration during tapping. However, the change in hearth bottom temperature is the result of formation and disappearance of low permeability zone in the hearth. ${ }^{4-7)}$ In terms of the refractory wear, the influences of low permeability zone on tap hole refractory wear is thought to be small. Actually, no significant difference in tap hole diameter enlargement was observed between operation (A) and (B). Hence, the other factors' contributions to control the tapping time or the drainage rate have to be con- sidered.

\section{Tap Hole Model}

\subsection{Fluid Path Model}

In order to explain the phenomena discussed above, a new model for the fluid path is proposed. In the model, the fluid path consists of coke particle packed layer and tap hole. As tapping progresses, particles diameter in coke layer becomes smaller and smaller due to carbon consumption as a result of dissolution into hot metal and reduction of $\mathrm{FeO}$ in slag and the tap hole diameter enlarges due to its wall wear. Under such condition, the drainage rate of fluid would be controlled by either of two factors, passing speed through coke packed layer and flow speed through tap hole.

The adequacy for introducing the coke packed layer in the model is supported by many investigations that coke is consumed not only by combustion at race way but also by dissolution into molten iron and/or slag at furnace hearth. Kushima et al.,${ }^{8)}$ by means of tracer injection experiment at commercially operated BF and its model experiment, conjectured of the coke vanishing zone at tap hole level, suggesting that coke particles are comminuted just below the race way and carbon unsaturated molten iron is dripped down around the furnace peripheral region at tap hole level. With numerical simulation on solid flow of coke particles in BF by experiments and discrete element method (DEM) calculations, Nouchi et al. ${ }^{9)}$ deduced that, if coke is consumed only in the race way, the stagnant zone coke cannot be renewed. Taking account of the coke consumption at tap hole level, they concluded the formation of low permeability zone.

Furthermore, other investigations also suggest the possibility of coke consumption around tap hole. Mitsufuji et $a l{ }^{10)}$ demonstrated that, based on analysis on the droplets whose sample was taken through tuyere, high $\mathrm{FeO}$ content molten slag and low carbon content molten metal are dripping from the race way. Sun ${ }^{11)}$ concluded that the carbon dissolution rate into molten iron is regulated by mass transfer and its driving force is the difference in carbon content between $\mathrm{C}$ saturated iron ([C] $]^{\text {sat }}$ ) and referent iron ([C]). Sunahara et al. ${ }^{12)}$ investigated that coke particles are consumed as a result of reduction of $\mathrm{FeO}$ in dripping slag and evaluated the overall reaction rate constant of coke dissolution reaction into molten $\mathrm{FeO}$ by experiment. Post et al. ${ }^{13)}$ presented that, in accordance with coke particle diameter diminishing due to its dissolution, the void fraction of dead man is increased. Though these investigations ${ }^{10-13)}$ do not directly mention of the coke consumption at tap hole level, they indicate the likelihood and possibility that coke is consumed near tap hole.

\subsection{Mathematical Model}

Indicating the parameters necessary for the numerical calculation, Fig. 9 shows the model. In the model, one end of tap hole tube contacts with coke particles packed layer (hereinafter, referred to as "coke filter"). The drainage rates in coke filter and tap hole tube are controlled by pressure drop in corresponding region. The relation between pressure drop and fluid flow rate in the coke filter can be described by Kozeny-Carman equation (Eq. (1)) and that in 


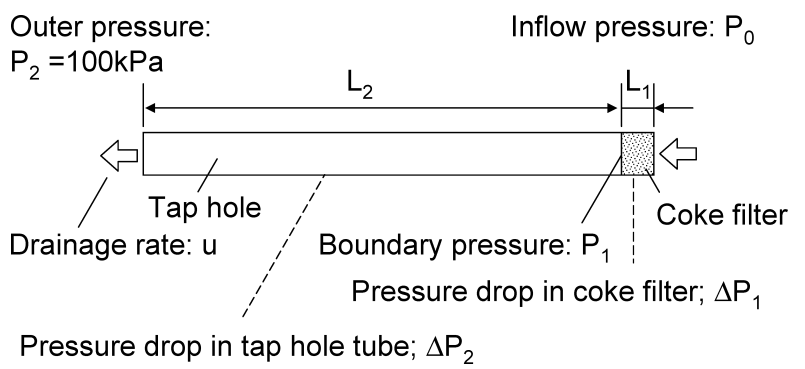

Fig. 9. Schematic diagram of mathematical model.

the tap hole tube can be expressed by Darcy Weisbach equation (Eq. (2)). In the presenting flow condition, friction factor (f) in Eq. (2) can be calculated by Nikuradse equation (Eq. (3)).

$$
\begin{aligned}
& \Delta P_{1}=\frac{180 u \cdot \mu \cdot L_{1}}{D^{2}} \cdot \frac{(1-\varepsilon)^{2}}{\varepsilon^{3}} \\
& \Delta P_{2}=f \frac{L_{2}}{d} \cdot \frac{\rho \cdot u^{2}}{2} \\
& f=0.0032+\frac{0.221}{\operatorname{Re}^{0.237}} \\
& \Delta P_{1}=P_{0}-P_{1} \\
& \Delta P_{2}=P_{1}-P_{2}
\end{aligned}
$$

where, $\Delta P_{1}$ : pressure loss at coke filter,

$u$ : fluid flow rate,

$\mu$ : viscosity of fluid,

$L_{1}$ : coke filter thickness,

$D$ : coke particle diameter,

$\rho$ : density of fluid,

$\varepsilon$ : void fraction of coke filter,

$\Delta P_{2}$ : pressure loss at tap hole tube,

$d$ : tap hole diameter,

$f$ : friction factor of tap hole tube,

$L_{2}$ : tap hole tube length (excluding coke filter),

Re : Reynolds number $(u L /(\mu / \rho))$.

Defining the in-flow pressure as $P_{0}$, the pressure at the boundary where coke filter and tap hole tube contact each other as $P_{1}$, and the outer pressure as $P_{2}$, the pressure drops $\Delta P_{1}$ and $\Delta P_{2}$ can be simply expressed as in Eqs. (4) and (5), respectively. Since the fluid entry of tap hole tube directly connects to coke filter, the flow rate $(u)$ and the pressure $\left(P_{1}\right)$ share identical values at the boundary. Thus, $u$ and $P_{1}$ can be obtained as solution of simultaneous equations of Eqs. (1) and (2).

Change rates of drainage speed in coke filter and tap hole tube can be expressed with difference equations using the change rates of coke particle diameter $(D)$ and tap hole tube diameter $(d)$, respectively. Referring to the analysis made by Sun ${ }^{11)}$ and Sunahara et al., ${ }^{12)}$ the time dependency of coke particle diameter is calculated.

Sun $^{11)}$ presented the carbon dissolution rate into molten iron as mass transfer process of which driving force was $[\mathrm{C}]^{\text {sat }}-[\mathrm{C}]$, as shown in Eq. (6).

$$
J_{\mathrm{d}}=\left(A \kappa_{\mathrm{m}} \rho_{\mathrm{m}} / 100\right) \cdot\left([\mathrm{C}]^{\mathrm{sat}}-[\mathrm{C}]\right)
$$

where, $J_{\mathrm{d}}$ : dissolving rate of carbon $\left(\mathrm{g} \cdot \mathrm{s}^{-1}\right)$,

$A$ : solid-liquid contact area $\left(\mathrm{cm}^{2}\right)$,

$\kappa_{\mathrm{m}}$ : mass transfer coefficient $\left(\mathrm{cm} \cdot \mathrm{s}^{-1}\right)$,

$\rho_{\mathrm{m}}$ : liquid density $\left(\mathrm{g} \cdot \mathrm{cm}^{-3}\right)$,

$[\mathrm{C}]^{\text {sat }}$ : saturated carbon content (mass $\left.\%\right)$,

$[\mathrm{C}]$ : carbon content in molten iron (mass $\%$ ).

Sun $^{11)}$ obtained $0.00286 \mathrm{~cm} / \mathrm{s}$ as $\kappa_{\mathrm{m}}$ at $1773 \mathrm{~K}$ by experiment.

Sunahara et al. $^{12)}$ expressed the reaction rate between coke and molten $\mathrm{FeO}$ as surface reaction process, as shown in Eq. (7).

$$
k=0.19 e^{-85700 /(R T)}
$$

where, $k$ : overall reaction rate constant $\left(\mathrm{cm} \cdot \mathrm{s}^{-1}\right)$,

$R: \quad \operatorname{gas}$ constant $\left(\mathrm{J} \cdot \mathrm{K}^{-1} \cdot \mathrm{mol}^{-1}\right)$,

$T$ : Temperature (K).

Based on the experimental result, overall reaction rate constant $(k)$ is given as $5.68 \times 10^{-6}\left(\mathrm{~m} \cdot \mathrm{s}^{-1}\right)$ at $1773 \mathrm{~K}$. Since the value is for reaction between coke particle and molten $\mathrm{FeO}$, reaction rate constant between coke and molten slag is obtained by multiplying $\mathrm{FeO}$ fraction in slag. Although mole fraction of $\mathrm{FeO}$ should be required for calculation, mass fraction of $\mathrm{FeO}$ is applied as approximate value since $\mathrm{FeO}$ variation in slag is small (less than $1 \mathrm{mass} \%$ ) in the subject.

Combing Eqs. (6) and (7), dissolving rate of coke particle $\left(\mathrm{dV}_{\text {coke }}\right)$ at $1773 \mathrm{~K}$ is expressed by Eq. (8).

$$
\begin{aligned}
& \mathrm{dV}_{\text {coke }}=A \cdot\left\{2.86 \cdot 10^{-5} \cdot\left([\mathrm{C}]^{\text {sat }}-[\mathrm{C}]\right) \cdot\left(1-\mathrm{SR}_{(\mathrm{V})}\right)\right. \\
& \left.+5.68 \cdot 10^{-6} \cdot \mathrm{FeO}_{\text {slag }} \cdot \mathrm{SR}_{(\mathrm{V})}\right\} \text {....... }
\end{aligned}
$$

where, $\mathrm{dV}_{\text {coke }}$ : dissolving rate of coke particle $\left(\mathrm{m}^{3} \cdot \mathrm{s}^{-1}\right)$, $A$ : solid-liquid contact area $\left(\mathrm{m}^{2}\right)$,

$\mathrm{SR}_{(\mathrm{V})}$ : volume fraction of slag in liquid $(-)$,

$\mathrm{FeO}_{\text {slag }}$ : mass fraction of $\mathrm{FeO}$ in slag $(-)$.

Assuming that coke particles are spherical, the change of coke particle diameter can be calculated by $[\mathrm{C}]^{\text {sat }}-[\mathrm{C}]$ in metal, FeO in slag and slag/metal ratio.

Based on the conclusion described by Post et al. ${ }^{13)}$ that void fraction of dead man increases and pressure drop decrease as coke particle dissolve into the liquid, it was assumed that total number of coke particles in coke filter is constant during tapping. Figure $\mathbf{1 0}$ shows the schematic illustration about coke consumption during tapping according to the experimental result investigated by Post et al., ${ }^{13)}$ who presented the dissolving behavior of packed bed of

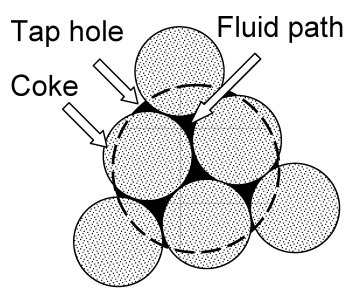

(a) Initial stage of tapping

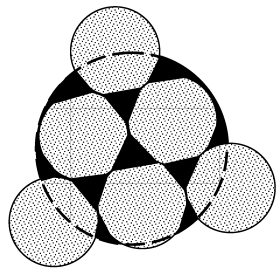

(b) Tapping progress
Fig. 10. Schematic illustration of coke consumption during tapping. 
Table 1. Base conditions of calculations for BF "A".

\begin{tabular}{|c|c|c|}
\hline Production $/ \mathrm{td}^{-1}$ & Prod & 10,000 \\
\hline Slag ratio / - & $S r$ & 0.3 \\
\hline Initial coke radius $/ \mathrm{m}$ & $r_{\text {coke } 0}$ & 0.02 \\
\hline Initial void fraction / - & $\varepsilon_{0}$ & 0.32 \\
\hline Mass transfer coefficient in Metal / $\mathrm{ms}^{-1}$ & $\kappa_{m}$ & $2.86 \times 10^{-5}$ \\
\hline Saturated carbon concentration in liquid / mass $\%$ & {$[C]^{s a t}$} & 5.0 \\
\hline Carbon concentration in liquid / mass $\%$ & {$[C]$} & 4.9 \\
\hline Overall reaction rate constant in $\mathrm{FeO} / \mathrm{ms}^{-1}$ & $k$ & $5.68 \times 10^{-6}$ \\
\hline $\mathrm{FeO}$ fraction in slag / mass $\%$ & $\mathrm{Fe} O_{\text {slag }}$ & 0.30 \\
\hline Slag density / kgm ${ }^{-3}$ & $\rho_{s}$ & 2800 \\
\hline Metal density / kgm ${ }^{-3}$ & $\rho_{m}$ & 6700 \\
\hline Slag viscosity / $\mathrm{Pa} \cdot \mathrm{s}$ & $\mu_{s}$ & 0.435 \\
\hline Metal viscosity / $\mathrm{Pa} \cdot \mathrm{s}$ & $\mu_{m}$ & 0.006 \\
\hline Inflow pressure $/ \mathrm{kPa}$ & $P_{0}$ & 400 \\
\hline Outer pressure / $\mathrm{kPa}$ & $P_{2}$ & 100 \\
\hline Length of coke filter $/ \mathrm{m}$ & $L_{1}$ & 0.08 \\
\hline Tap hole length / m & $L_{2}$ & 3.5 \\
\hline Initial tap hole diameter $/ \mathrm{m}$ & $d_{0}$ & 0.060 \\
\hline Tap hole diameter enlargement rate $/ \mathrm{ms}^{-1}$ & $\Delta d$ & $1.0 \times 10^{-6}$ \\
\hline Tap hole length shortening rate $/ \mathrm{ms}^{-1}$ & $\Delta L_{2}$ & 0.0 \\
\hline
\end{tabular}

benzoic acid spheres in running water. Gaps between coke particles are regarded as fluid paths. It is reasonable to hypothesize that coke particle size diminishes as to enlarge the fluid paths since the dissolving reaction occurs at contact surfaces between coke particles and the liquid. Therefore, it was assumed that number of particle in coke filter during tapping is constant.

Based on the assumption, the change of void fraction in coke filter is calculated from coke particle diameter change;

$$
\begin{aligned}
& \varepsilon_{0}=1-n \cdot V_{\text {coke } 0} \\
& n=\left(1-\varepsilon_{0}\right) / V_{\text {coke }} \\
& \varepsilon=1-n \cdot V_{\text {coke }}=1-\left(1-\varepsilon_{0}\right) / V_{\text {coke } 0} \cdot V_{\text {cok }}
\end{aligned}
$$

where, $\varepsilon_{0}$ : initial void fraction in coke filter,

$\varepsilon$ : void fraction of coke filter,

$V_{\text {coke } 0}$ : initial volume of a coke particle,

$n$ : number of coke particles in coke filter.

At each time step in the simulative calculation, $u$ and $P_{1}$ were obtained by Newton method, which enabled to calculate the drainage rate at each time step. Defining that tapping time in the model is the point of time when the accumulated drainage volume matches the accumulated production volume in furnace.

\subsection{Assumptions for Calculation}

Basic conditions for calculation in case of $\mathrm{BF}$ " $\mathrm{A}$ " are summarized in Table 1. For the purpose of comparing calculation results directly with the observed drainage rates shown in Fig. 8, proximate parameters are selected so as to represent the production conditions of BF "A" at observed operation period.

Initial coke particle diameter is assumed as $40 \mathrm{~mm}$ depending on the observations of the coke particles flowing out from tap hole of BF "B" as shown in Fig. 11. Since the authors are not aware of appropriate absolute values for $[\mathrm{C}]^{\text {sat }},[\mathrm{C}]^{\text {sat }}$ is simply assumed as 5.0 mass $\%$ because the calculation requires only the difference between two param-
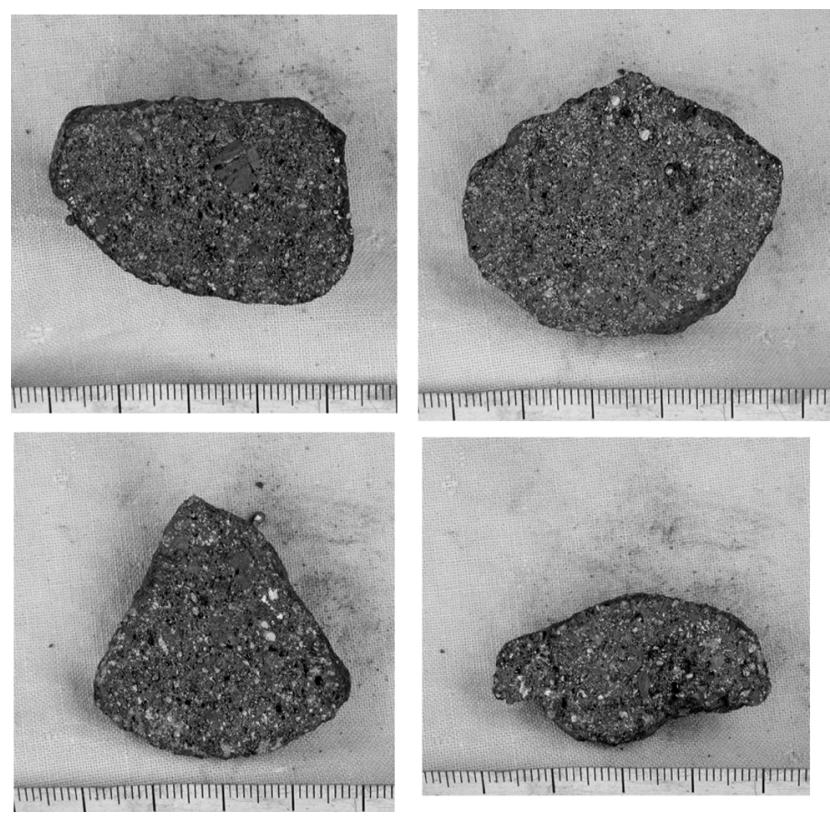

Fig. 11. Cut surfaces of coke flowing out from tap hole of BF "B".

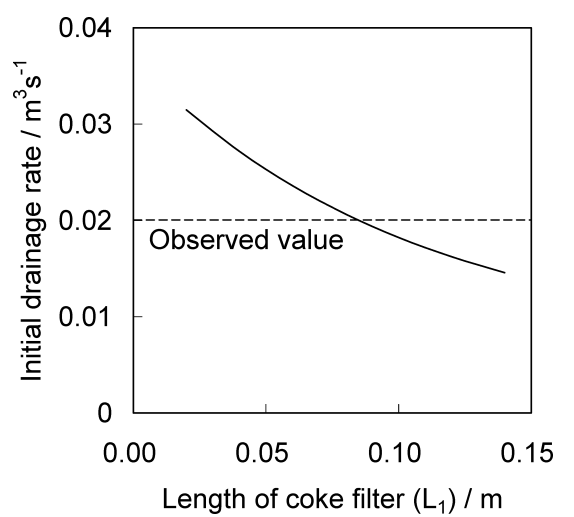

Fig. 12. Calculated initial drainage rate as a function of coke filter length.

eters, i.e. $[\mathrm{C}]^{\mathrm{sat}}-[\mathrm{C}]$. The density and viscosity of drained liquids are the mean value of iron and slag. Inflow pressure $\left(P_{0}\right)$ is assumed as $400 \mathrm{kPa}$ by referring to the blast pressure of actual BFs.

Length of coke filter $\left(L_{1}\right)$ is assumed as $0.08 \mathrm{~m}$ depending on the tuning calculation as follows. Since the coke filter of the proposed model is located in the hearth of actual $\mathrm{BFs}$, flow rate of the liquid decreases as increase in distance from tap hole entry point as shown in some investigations. ${ }^{1,13-15)}$ Taking the flow rate variation into account, the calculation becomes complicated. To simplify the calculation, the suitable length of coke filter for the calculation is tuned. Figure 12 shows change of calculated initial drainage rate as a function of coke filter length. Comparing the observed initial drainage rates (approximately $0.02 \mathrm{~m}^{3} / \mathrm{s}$ as shown in Fig. 8), $0.08 \mathrm{~m}$ is obtained as the adequate value for coke filter length in the model.

Tap hole diameter enlargement rate $(\Delta \mathrm{d})$ is also estimated by tuning calculation as shown in Fig. 13 which indicates changes of drainage rate variation during tapping at period (A) of BF "A". Depending on Fig. 13, $1.0 \times 10^{-6} \mathrm{~m} \mathrm{~s}^{-1}$ is selected as tap hole diameter enlargement rate. For calculations, $[\mathrm{C}]^{\text {sat }}-[\mathrm{C}]$ is assumed as 


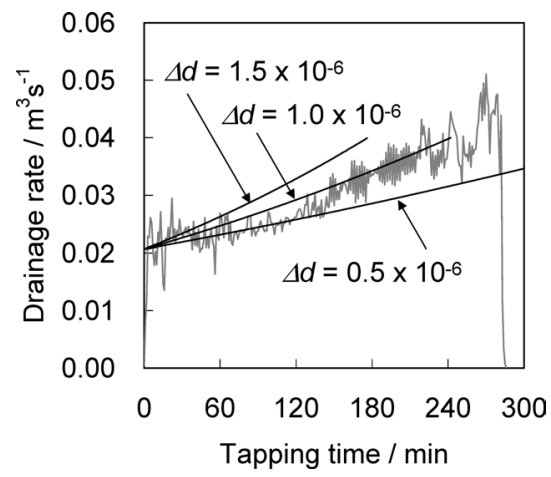

Fig. 13. Comparisons of drainage rate variation during tapping between observed and calculated. $\Delta d$ indicates tap hole diameter enlargement rate in $\mathrm{m} \mathrm{s}^{-1}$.

\section{$0.10 \operatorname{mass} \%$.}

In practice, tapping operations continue alternately. In the case, particle size and packing configuration of coke particle in the area which corresponds to the coke filter in the model changes gradually through several tapping operations. Nouchi et al. ${ }^{9)}$ investigated the renewal of coke network on the basis of model experiment and DEM calculation. Depending on the investigation, some new particles supposed to be supplied to the area while some particles dissolve into the liquid. For calculation, it is assumed that particle size and packing configuration in the coke filter are constant at the tapping start.

\section{Results and Discussion}

\subsection{Drainage Rate Variation during Tapping}

According to Fig. 8, carbon content in metal was lower at the period (B) at which the hearth bottom temperature was lower and the drainage rate acceleration was higher. Since the difference in carbon content was 0.24 mass $\%$, drainage rate variation was calculated in case of $[\mathrm{C}]^{\text {sat }}-[\mathrm{C}]=$ $0.34 \mathrm{mass} \%$ to compare the drainage rate variation at the period (A) in which $[\mathrm{C}]^{\text {sat }}-[\mathrm{C}]$ is assumed as $0.10 \mathrm{mass} \%$. Figure 14 shows the result. The calculated result traced the observed data with good conformity. Thus, it becomes possible to describe the drainage rate variation with constant the tap hole diameter enlargement rate.

Figure 15 shows the calculated results of the changes of coke particle diameter during tapping for both cases. The coke diameter decreases only $1 \mathrm{~mm}$ during tapping.

\subsection{Tapping Time Variation}

Figure 16 shows the comparisons of tapping time variation between observed values, which have been shown in Fig. 5, and calculated ones as a function of $\mathrm{FeO}$ fraction in slag at BF "B". Basic calculation condition for BF " $\mathrm{B}$ " is summarized in Table 2. Different values compared to the calculation for BF "A" are only the production of BF and the initial tap hole diameter. Variation of tapping time as a function of $\mathrm{FeO}$ fraction in slag is explainable with adjustment of the only one parameter, i.e. $[\mathrm{C}]^{\mathrm{sat}}-[\mathrm{C}]$ in pig iron.

\subsection{Influence of Initial Tap Hole Diameter on Tapping Time}

Although standard initial tap hole diameter of BF "B"

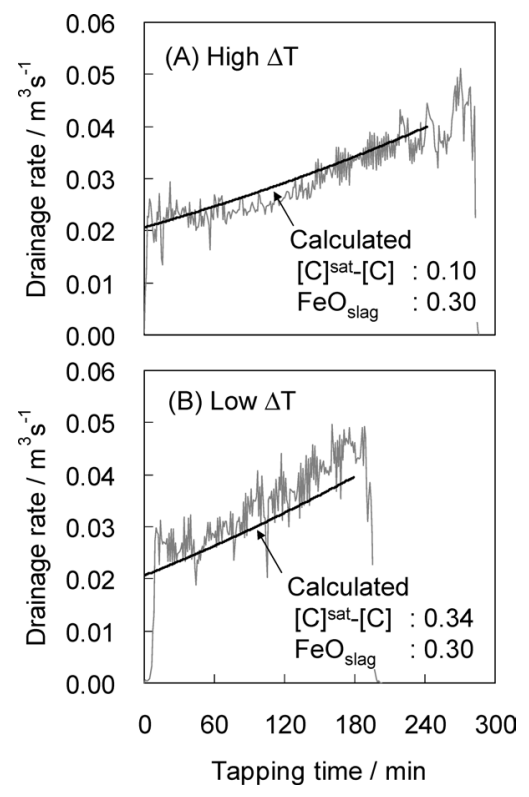

Fig. 14. Comparisons of drainage rate change of $(A)$ and $(B)$ at $\mathrm{BF}$ "A" between calculation and observed.

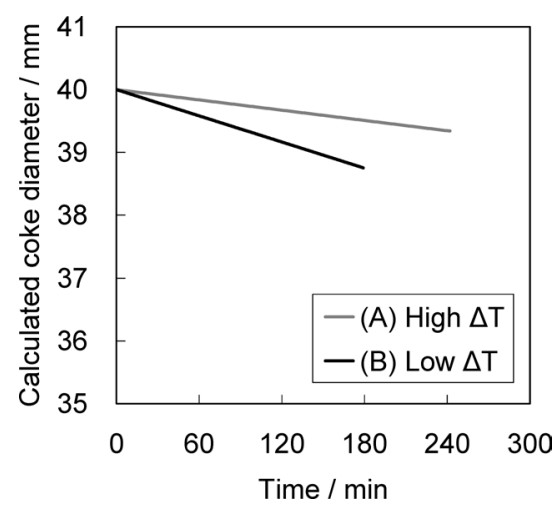

Fig. 15. Calculated changes of coke diameter in coke filter during tapping in case of (A) and (B) at BF "A" .

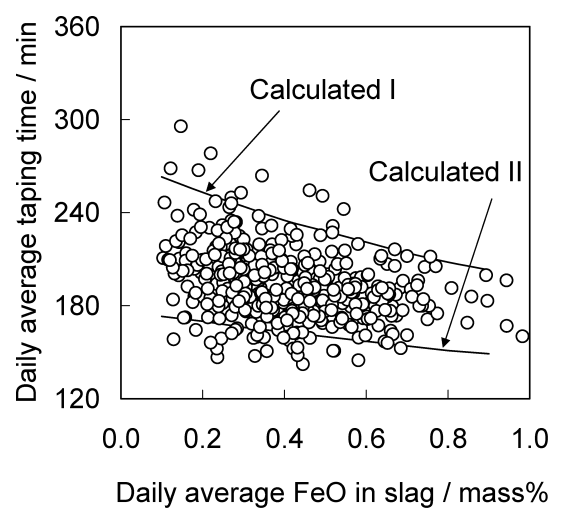

Calculated I : [C] $]^{\text {sat_}}[\mathrm{C}]=0.10$ mass $\%$

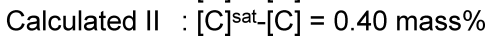

Fig. 16. Comparisons of tapping time dependencies on $\mathrm{FeO}$ fraction in slag at BF " $\mathrm{B}$ " between calculation and observed.

have been $67 \mathrm{~mm}, 70 \mathrm{~mm}$ had been applied for $5 \mathrm{~d}$ as an experiment. Figure 17 shows the influence of initial tap hole diameter on tapping time. Basic condition for calculation is same as shown in Table 2. The good fit was achieved with the observed data. The larger initial tap hole diameter 
Table 2. Base conditions of calculations for BF "B".

\begin{tabular}{|l|c|c|}
\hline Production / $\mathrm{td}^{-1}$ & Prod & 12,500 \\
\hline Slag ratio / - & $S r$ & 0.3 \\
\hline Initial coke radius / $\mathrm{m}$ & $r_{\text {cokeo }}$ & 0.02 \\
\hline Initial void fraction / - & $\varepsilon_{0}$ & 0.32 \\
\hline Mass transfer coefficient in Metal / $\mathrm{ms}^{-1}$ & $\kappa_{m}$ & $2.86 \times 10^{-5}$ \\
\hline Saturated carbon concentration in liquid / mass\% & {$[C]^{\text {sat }}$} & 5.0 \\
\hline Carbon concentration in liquid / mass\% & {$[C]$} & 4.85 \\
\hline Overall reaction rate constant in $\mathrm{FeO} / \mathrm{ms}^{-1}$ & $k$ & $5.68 \times 10^{-6}$ \\
\hline FeO fraction in slag / mass\% & $F e O_{\text {slag }}$ & 0.30 \\
\hline Slag density / kgm ${ }^{-3}$ & $\rho_{s}$ & 2800 \\
\hline Metal density / kgm ${ }^{-3}$ & $\rho_{m}$ & 6700 \\
\hline Slag viscosity / Pa $\cdot \mathrm{s}$ & $\mu_{s}$ & 0.435 \\
\hline Metal viscosity / Pa $\cdot \mathrm{s}$ & $\mu_{m}$ & 0.006 \\
\hline Inflow pressure / $\mathrm{kPa}$ & $P_{o}$ & 400 \\
\hline Outer pressure / $\mathrm{kPa}$ & $P_{2}$ & 100 \\
\hline Length of coke filter / m & $L_{I}$ & 0.08 \\
\hline Tap hole length / m & $L_{2}$ & 3.5 \\
\hline Initial tap hole diameter / m & $d_{o}$ & 0.067 \\
\hline Tap hole diameter enlargement rate / $\mathrm{ms}^{-1}$ & $\Delta d$ & $1.0 \times 10^{-6}$ \\
\hline Tap hole length shortening rate / $\mathrm{ms}^{-1}$ & $\Delta L_{2}$ & 0.0 \\
\hline
\end{tabular}

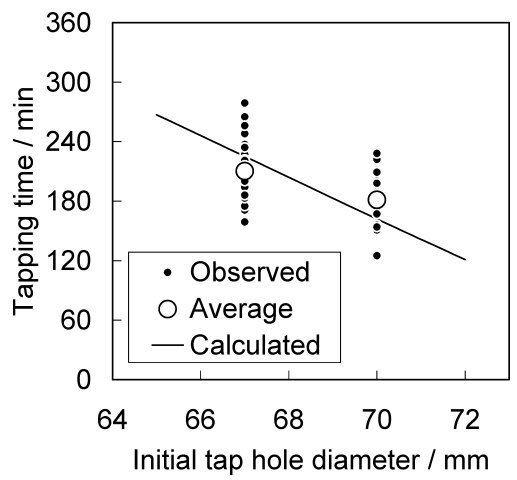

Fig. 17. Comparisons of tapping time dependencies on initial tap hole diameter at $\mathrm{BF}$ "B" between calculation and observed.

brings shorter tapping time and the ratio in tapping time $(86 \%)$ is larger than simply expected by the ratio in initial tap hole sectional area (109\%). This can be attributed to the mass balance between liquid droplet supply onto hearth and its drainage through tap hole especially at the initial stage of tapping operation.

\subsection{Relation between Hearth Bottom Temperature and Tapping Time}

Based on the conclusive result that $[\mathrm{C}]^{\text {sat }}-[\mathrm{C}]$ in pig iron strongly influences on tapping time, relation between hearth bottom temperature and tapping time is discussed in this section. The change of hearth bottom temperature is explained as results of formation/elimination of low permeability zone. ${ }^{4-7)}$ When apprehensive explanation for the relation between low permeability zone formation/elimination and $[\mathrm{C}]^{\text {sat }}-[\mathrm{C}]$ is attained, therefore, the reasonableness of the calculation results and the introduced model can be assured.

The schematic images of hearth bottom with or without low permeability zone are shown in Fig. 18. Under the low hearth bottom temperature condition in which the entire hearth is suffused with the low permeability zone, the average traveling time of pig iron in coke particles mixed metal

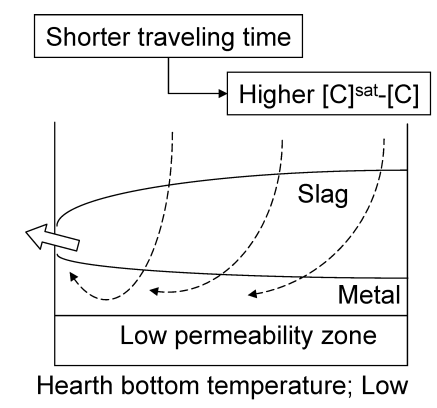

(a) Lower bottom temperature period

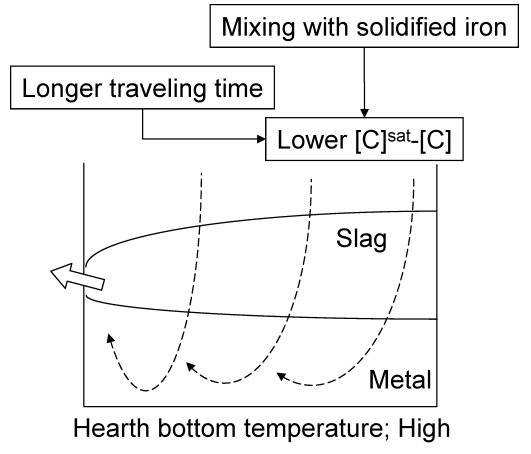

(b) Higher bottom temperature period

Fig. 18. Schematic illustration for effect of low permeability zone on [C].

pool from dripping into hearth to reaching tap hole entry position is thought to be shorter due to the shallow metal bath. Subsequently, the degree of $\mathrm{C}$ saturation of iron entering into the modeled tap hole is small, i.e. large $[\mathrm{C}]^{\text {sat }}-[\mathrm{C}]$.

On the contrary, under the high hearth bottom temperature condition with elimination of low permeability zone, the average traveling time of pig iron in heath metal pool becomes longer, resulting in highly $\mathrm{C}$ saturated at the tap hole entry point. Taking into consideration of the likelihood that, at high hearth bottom temperature, solidified iron on hearth can be melted and mixed with liquid iron, pig iron $\mathrm{C}$ saturation level becomes close to its equilibrium. $\mathrm{C}$ content in solidified iron is considered to be higher due to longer remaining time on hearth before complete solidification.

Since $[\mathrm{C}]^{\text {sat }}$ in pig iron is influenced by small quantity components, it is difficult to determine the strict value of $[\mathrm{C}]^{\text {sat}}-[\mathrm{C}]$. However, positive correlation of tapped [C] and hearth bottom temperature (as shown in Fig. 6) suggests the relation between hearth bottom temperature and $\mathrm{C}$ saturation revel in pig iron as discussed above.

\subsection{Influence of Other Parameters on Tapping Time}

By changing other parameters in the introduced mathematical model, the influences of tap hole diameter enlargement rate, initial coke diameter, and initial void fraction in coke filter on tapping time are examined. Base conditions of the calculations are same as shown in Table 1. These results are shown in Figs. 19-21.

Figure 19 shows the influence of tap hole diameter enlargement rate on the tapping time. Since the tap hole diameter enlargement depends on tap hole mix durability or wear rate, the calculation result indicates the effect of tap hole mix performance. According to the calculation in case of $[\mathrm{C}]^{\text {sat }}-[\mathrm{C}]=0.1 \mathrm{mass} \%$, harf of tap hole diameter enlargement rate causes 1.6 times longer tapping time (from 


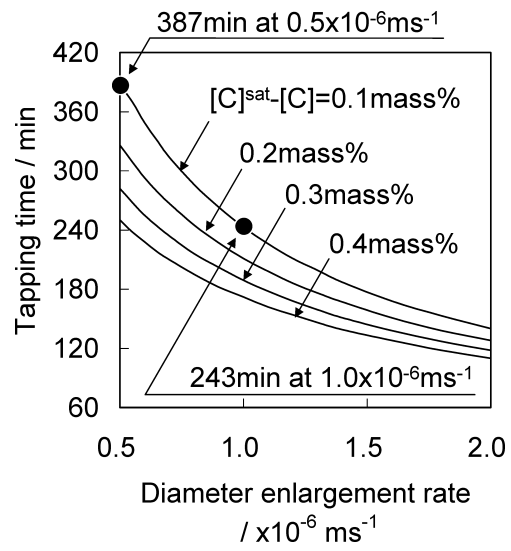

Fig. 19. Change of tapping time as a function of tap hole diameter enlargement rate.

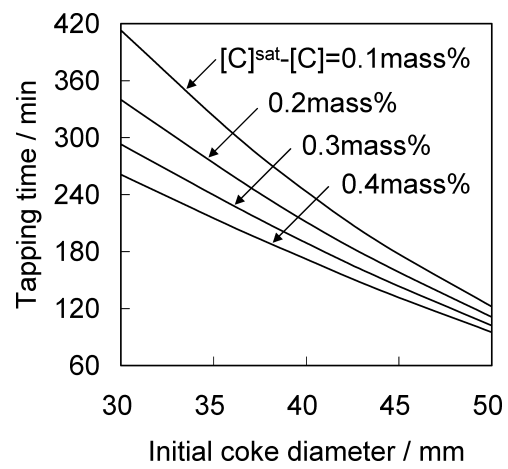

Fig. 20. Change of tapping time as a function of initial coke diameter.

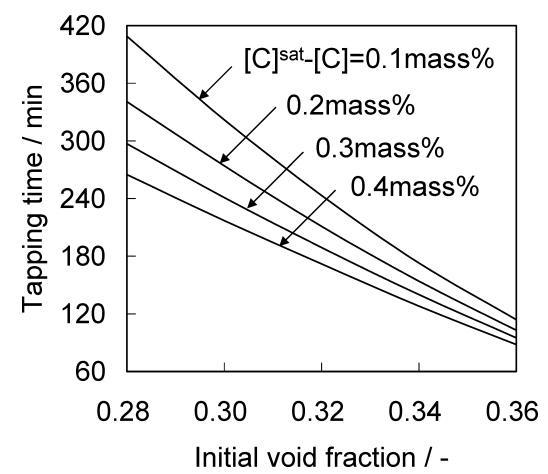

Fig. 21. Change of tapping time as a function of initial void fraction.

$243 \mathrm{~min}$ at $1.0 \times 10^{-6} \mathrm{~m} \mathrm{~s}^{-1}$ of wear rate to $387 \mathrm{~min}$ at $0.5 \times 10^{-6} \mathrm{~m} \mathrm{~s}^{-1}$ of wear rate).

As shown in Figs. 20 and 21, the influences of both initial coke diameter and initial void fraction in coke filter on tapping time are remarkably significant. The results can be comprehended that, due to small initial coke diameter or low void fraction, the pressure drop in coke filter layer becomes big and lessens the flow rate there. It can be concluded, therefore, that the coke particles' size and their packing configuration in coke filter layer have important role to control the drainage rate or tapping time as well as the tap hole diameter enlargement. The conclusions suggest the difficulties to make a proper evaluation on the improvement of tap hole mix durability at practical experiments at commercial BFs.

\section{Conclusions}

In the practical BF operation, the drainage rate or tapping time broadly varies. Despite the indication given by Nishioka et al. ${ }^{1)}$ that the change in drainage rate could not be explained only by tap hole diameter enlargement, the question for what are the dominant factors to control the drainage rate has been remained.

In order to evaluate the main factors to control the liquid drainage rate or tapping time at $\mathrm{BF}$, the authors introduced a simulative calculation model, in which the liquid drainage path consists of coke particles packed layer (coke filter) and tapping hole. Referring to the study by Sun ${ }^{11)}$ and Sunahara et al., ${ }^{12)}$ a hypothesis that iron and slag in coke filter is driven toward the tap hole entry point consuming or reacting with the coke particles, whose extent depends on molten iron $\mathrm{C}$ saturation degree and $\mathrm{FeO}$ fraction in molten slag was introduced. In short, the overall drainage rate is calculated by pressure drops both in coke filter and tapping hole.

The calculation results present good matches with the observed tapping operation at BFs " $\mathrm{A}$ " and " $\mathrm{B}$ ", whose practical operation parameters were applied in the simulation as they were. A notable calculation result is that pig iron $\mathrm{C}$ saturation level is thought to be the dominant factor to control the drainage rate as well as to represent the influence of hearth bottom temperature on drainage rate or tapping time observed in commercial operation. Combining the two influences of low permeability zone formation, ${ }^{4-7)}$ (1) to lower the hearth bottom temperature and (2) to induce low $\mathrm{C}$ saturation of fluid iron due to shorter traveling time toward the tap hole entry point, the obtained calculation results are explainable.

The calculation results also indicate of the important role of coke particle size and/or packing configuration in coke filter for controlling the drainage rate as well as the tap hole diameter enlargement.

\section{REFERENCES}

1) K. Nishioka, T. Maeda and M. Shimizu: ISIJ Int., 45 (2005), No. 5, 669.

2) H. Yamanaka, S. Fujihara, T. Ando, F. Naito, Y. Tsugita, T. Ishibashi and N. Wada: Refractories (Taikabutsu), 35 (1983), No. 11, 623.

3) T. Ando, M. Nagahara, S. Fujiwara, Y. Murai, M. Nomura and M. Nose: Tetsu-to-Hagané, 70 (1984), s71.

4) Y. Sawa, K. Takeda, S. Taguchi, T. Matsumoto, Y. Watanabe and H. Kamano: Tetsu-to-Hagané, 78 (1992), No. 7, 1171.

5) K. Takeda, S. Watakabe, Y. Sawa, H. Itaya, T. Kawai and T. Matsumoto: Iron Steelmaker, 27 (2000), No. 3, 79.

6) T. Orimoto, K. Kunitomo and M. Isobe: CAMP-ISIJ, 19 (2006), 705.

7) A. Shinotake and K. Kunitomo: CAMP-ISIJ, 19 (2006), 706.

8) Y. Kushima, S. Arino, J. Ono, M. Nakamura and K. Tachimori: Tetsu-to-Hagané, 71 (1985), s65.

9) T. Nouchi, T. Sato, M. Sato, K. Takeda and T. Ariyama: ISIJ Int., 45 (2005), No. 10, 1426.

10) H. Mitsufuji, M. Sakurai, A. Maki, T. Sumigawa and Y. Niwa: Tetsuto-Hagané, 78 (1992) No. 7, 1148.

11) H. Sun: ISIJ Int., 45 (2005), No. 10, 1482.

12) K. Sunahara, T. Inada and Y. Iwanaga: Tetsu-to-Hagané, 78 (1992), No. 7, 1156.

13) J. R. Post, C. Tognarelli, J. V. D. Stel, Y. Yang and M. A. Reuter: ECIC 2005, Tu4:4-1.

14) M. Tchimori, J. Ohno, M. Nakamura and Y. Hara: Tetsu-to-Hagané, 70 (1984), No. 16, 2224

15) K. Shibata, Y. Kimura, M. Shimizu and S. Inaba: ISIJ Int., 30 (1990), No. 3, 208. 